\title{
CARACTERÍSTICAS DA CAMADA LIMITE ATMOSFÉRICA TROPICAL (CLAT) NA REGIÃO DE SERPONG - INDONÉSIA DURANTE AS ESTAÇÕES SECA E CHUVOSA.
}

\author{
JOSÉ FRANCISCO DE OLIVEIRA JÚNIOR ${ }^{1}$ e BYUNG HYUK KWON ${ }^{2}$ \\ ${ }^{1}$ Universidade Federal do Alagoas - Departamento de Meteorologia -UFAL. \\ Tabuleiro dos Martins, Br. 104, km 14, CEP: 57072-970, Maceió, AL, Brasil.
}

Doutorando em Engenharia Civil, Ciências Atmosféricas, NCQAr-LAMCE, COPPE/UFRJ, Rio de Janeiro, RJ, Núcleo Computacional de Qualidade do Ar, Laboratório de Métodos Computacionais em Engenharia

E-mail : junior_inpe@hotmail.com-juninho@acd.ufrj.br-juninho@coc.ufrj.br

${ }^{2}$ Pukyong National University, Department of Environmental Atmospheric Sciences. Busan, 608-737, South Korea, E-mail :bhkwon@mail1.pknu.ac.kr

Recebido Abril 2005 - Aceito Novembro 2005

\begin{abstract}
RESUMO
Através dos dados de superfície, radiossondagem e radar Doppler banda - L, em Serpong Indonésia (6 24' S - $106^{\circ} 42^{\prime} \mathrm{E}$ ), durante a estação seca (1993) e chuvosa (1994) foram estudadas as características da CLAT. Os dados de radar foram validados através da radiossondagem por métodos estatísticos (índice de correlação, média e desvio padrão). A estrutura da CLAT foi interpretada através do eco de radar (vento), observado continuamente para todos os dias do período de estudo. As características mais evidentes da CLAT nesta região foram à presença de uma CM (Camada de Mistura) diurna que atingia a $0,3 \mathrm{~km}$ pela manhã e outra camada entre 3-5 km à tarde, observandose um ciclo diurno de crescimento e estacionariedade, devido ao aquecimento e resfriamento da superfície. A principal característica entre as estações foi que no horário de 0300 TL (Tempo Local), ambas apresentavam o mesmo comportamento (intensidade e direção do vento), mas para o restante do dia existiu uma grande diferença entre elas. Na estação seca a intensidade e a direção do vento foi mais variável do que na chuvosa, resultado observado na altura da CLAT. As informações obtidas através do BLR (Boundary Layer Radar), mostram a existência de pronunciadas variações diurnas na CLAT em dias claros. Verificou-se que a variação diurna da CLAT teve uma influencia marcante, devido à existência da circulação de brisa marítima, confirmada pelo BLR no dia 12/10/93. A validação dos dados do radar apresentou resultados significativos, onde na estação seca, os coeficientes de regressão variaram entre 0,83 e 0,94 , tanto na direção como na intensidade, e na chuvosa variou de 0,77 a 0,88 (intensidade) e na direção da ordem de 0,3 . Comprovou-se que as medidas de radar são equivalentes ao de radiossondagem, com o benefício de poder ter dados contínuos, provando-se que as observações, a partir da sua utilização deve desempenhar um papel importante no estudo da baixa atmosfera tropical.
\end{abstract}

Palavras-chave: radiossondagem, radar Doppler, brisa marítima, Indonésia.

\footnotetext{
ABSTRACT: TROPICAL ATMOSPHERIC BOUNDARY LAYER (BLAT) CHARACTERISTIC IN SERPONG - INDONESIA REGION, DURING DROUGHT AND RAINY SEASONS.

From the surface, radiosonde and Doppler radar Band - L data in Serpong, Indonesia $\left(6^{\circ} 24\right.$ ' S $106^{\circ} 42^{\prime} \mathrm{E}$ ), measured were performed during drought (1993) and rainy (1994) seasons, when BLAT characteristics were studied. Radar data were validated with soundings through statistical methods (correlation index, average and standard deviation). BLAT structure were interpreted through radar echo (wind), continuously observed through day over study period. BLAT evident characteristics in this region had been associated to diurnal ML (Mixing Layer) that reached $0.3 \mathrm{~km}$ at morning and $3-5 \mathrm{~km}$ at afternoon, were observed a steady and growth diurnal cycle, due to heating and cooling surface. Main characteristics between seasons were at 0300 LT (Local Time) presents intensity and direction of wind behaviors, but still remained during day an ample distinction between them. In
} 
drought season, intensity and direction of wind were more changeable than rainy season, result observed in BLAT height. Acquired information under BLR (Boundary Layer Radar), shown the existence of pronounced diurnal sharp variation on BLAT in clear days. Were verified that BLAT diurnal variation had an evident influence to existence of breeze sea circulation confirmed by BLR in $12 / 10 / 93$ day. Radar data validation were carried through information of soundings and had presented significant resulting, where drought season regression coefficients had varied between 0.83 and 0.94 , as much as intensity as direction, and rainy season had been $0.77-0.88$ (intensity) and in direction they had been in order of 0.3 . Proved that radar measures are equivalents to soundings, with benefit to being able continuous data, proving that using observations must be important role in low level tropical atmosphere study.

Keywords: radiosonde, Doppler radar, breeze-sea, Indonesia.

\section{INTRODUÇÃO}

Nos últimos anos, tem-se dado um destaque singular ao estudo climatológico da CLA (Camada Limite Atmosférica), principalmente nas latitudes médias (Ecklund et al., 1988, Gage e Balsley; 1992, Angevine et al., 1994), pois esta camada é a interface do sistema superfície-atmosfera. Na CLA, as propriedades dos fluxos médios (momentum, calor e vapor d'água) e as nuvens têm um papel importante no clima de uma região (Stull, 1988). Portanto, para uma melhor compreensão desta camada são necessárias parametrizações das variáveis meteorológicas nela observadas, (Sorbjan, 1989). Segundo Riehl (1954), a região tropical apresenta variações diurnas e ciclos sazonais que são condicionados aos efeitos locais. Assim, a evolução típica diária e a dinâmica da Camada Limite Atmosférica Tropical (CLAT) necessita de um detalhamento climatológico através de observações meteorológicas contínuas (radar) e das técnicas clássicas (radiossondagem).

Os radares têm um papel importante no campo da Meteorologia, particularmente nos dias atuais (Browning e Atlas, 1966; Armijo, 1969), onde são tidos como um dos principais instrumentos de observação da atmosfera, devido à sua capacidade de quantificar e identificar remotamente os fenômenos atmosféricos, (Sauvageot, 1982; Doviak e Zrnic, 1984; Sauvageot, 1992). Porém, nas últimas três décadas, a estrutura vertical da atmosfera tem sido alvo de várias pesquisas, a partir da construção dos primeiros "radares Doppler". Com isso, alguns estudos foram realizados, incluindo, os radares meteorológicos, e principalmente os perfiladores de vento, (Doviak et al., 1990).

Por exemplo, alguns destes estudos verificaram que os ecos refletidos pela atmosfera são melhor observados em dias claros do que em chuvosos (Lhermite, 1966, Gage et al., 1980; Doviak et al., 1990), mostrando-se que a intensidade do eco de radar em ar claro foi fortemente dependente das características da intensidade da turbulência atmosférica, que por sua vez depende dos gradientes verticais de temperatura e umidade,
(Rogers et al., 1993). A turbulência produzida pelas variações dos gradientes de temperatura e umidade, produz variações do índice refrativo atmosférico, que por sua vez contribuem para uma maior variação da altura da CLA, a exemplo disso, o eco de radar observado na região de Taiwan em dias claros foi significativamente afetado, chegando à altura da CLA da ordem de $8 \mathrm{~km}$ (Chu e Su, 1999).

O radar Doppler consegue obter uma boa resolução em ângulo ou em alcance dentro de uma ou mais dimensões e fornece dados de forma seqüenciada, sendo útil no entendimento das características ocorridas dentro da atmosfera, (May e Wilczak, 1993). A obtenção das componentes do campo do vento medidas pelo radar Doppler requer um posicionamento geométrico adequado, (Bousquet e Chong, 1997). Hashiguchi et al. (1995a) verificaram que a combinação radar Doppler/radiossondagem complementam satisfatoriamente as técnicas clássicas (balões cativos, aeronaves e torres anemométricas) quando o objetivo for à descrição da baixa troposfera, pois a metodologia clássica não pode observar detalhadamente esta camada (Rogers et al., 1993).

Dentre as diferentes regiões tropicais existentes no globo, pode-se destacar como sendo de grande importância para o clima global, a região da Indonésia, em função da pouca variação diurna na sua temperatura superficial oceânica; (Tsuda et al., 1995) e outro aspecto refere-se ao comportamento do escoamento atmosférico ser controlado pelas circulações de origem térmica e baseado no conjunto oceano-vento, sendo elas: Oceano Pacífico-Ventos Alísio (leste) e Oceano Índico-Monção (oeste), (Hashiguchi et al., 1995a; Tsuda et al., 1995). A compreensão destes sistemas de ventos é de grande relevância no estudo da variabilidade interanual do sistema oceano-atmosfera-superfície, (Tsuda et al., 1995). No estudo da CLAT, Hashiguchi et al. (1995b) utilizaram dois radares, o BLR (Boundary Layer Radar) e MWR (Meteoro Wind Radar) em Serpong-Indonésia, observando-se que a altura da CLAT foi de aproximadamente $4 \mathrm{~km}$ (MWR) e de 5 km (BLR), ao contrário de Tsuda et al. (1994b) que encontraram a CLAT próximo de $5 \mathrm{~km}$ de altura, a partir 
do uso do BLR em conjunto com o RASS (Radio Acoustic Sounding System).

Logo, o objetivo deste trabalho foi estudar as variações diurnas e sazonais, bem como os aspectos dinâmicos e termodinâmicos que caracterizam e controlam a CLAT na região de Serpong-Indonésia. A partir disso, foi analisado o comportamento da CLAT através de perfis médios e alturas típicas, baseando-se em observações de um radar Doppler banda - L, radiossondagem e dados de superfície.

\section{METODOLOGIA}

\subsection{Localização e característica da área de estudo}

A Figura 1 mostra a localização da área de estudo, Serpong - Indonésia $\left(6^{\circ} 24^{\prime} \mathrm{S}-106^{\circ} 42^{\prime} \mathrm{E}, 50 \mathrm{~m}\right.$ acima do nível médio do mar), no oeste do Mar de Java. Localizada entre dois oceanos (Índico - Pacífico) e dois continentes (Ásia-Oceania). A Indonésia tem um clima fortemente condicionado pela estrutura insular e sua posição geográfica, uma vez que se situa transversalmente em relação ao Equador. O arquipélago possui uma característica sazonal baseada no regime de ventos dominantes, sendo eles: monções-estação chuvosa (dezembro a março), que assegura chuvas abundantes durante todo o período e ventos alísios-estação seca (junho a outubro), (Hashiguchi et al., 1995a; Tsuda et al., 1995).

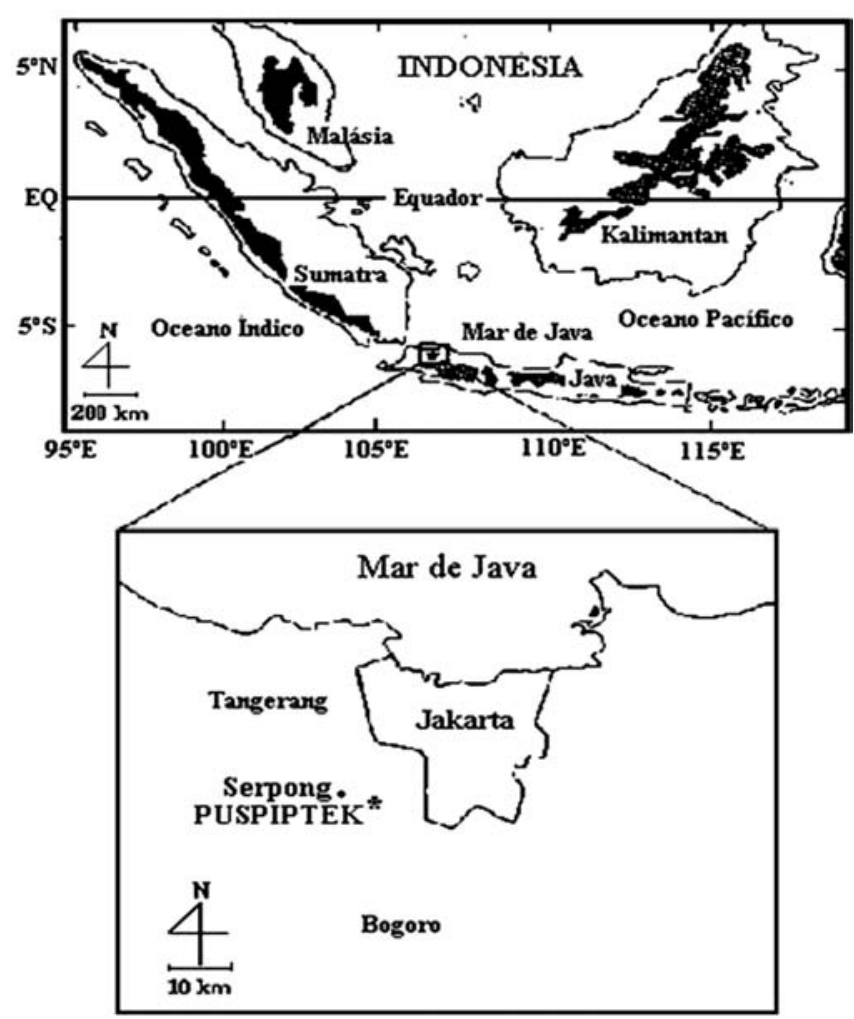

Figura 1 - Localização da área de estudo, Serpong - Indonésia.

\subsection{Instrumentação utilizada}

O radar utilizado neste estudo está localizado numa planície a aproximadamente $40 \mathrm{~km}$ do litoral do Mar de Java, conforme a Figura 2. Neste local foram monitoradas algumas variáveis meteorológicas, sendo elas: vento em superfície, temperatura do ar, umidade relativa, precipitação, radiação infravermelha e líquida. Além disso, foram realizadas duas campanhas de campo intensivas, sendo elas : estação seca (8-15 de outubro de 1993) e chuvosa (15-22 de fevereiro de 1994). Em cada campanha foram realizadas aproximadamente 50 radiossondagens com intervalo de 3 horas cada.

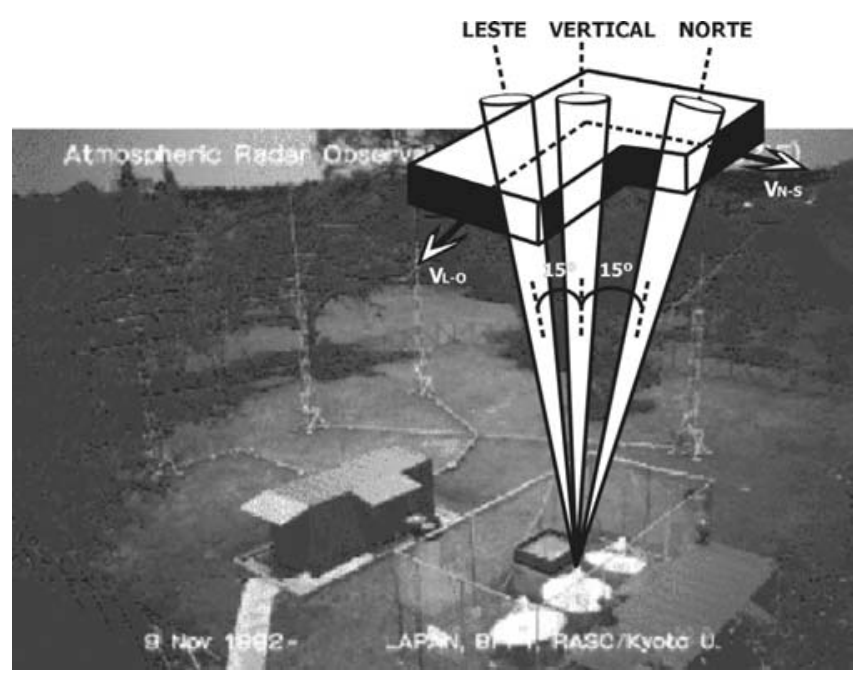

Figura 2 - Local do experimento do radar e o esquema do BLR utilizado na obtenção dos Dados de Eco Radar em Serpong - Indonésia. Fonte: Hashiguchi H. et al. (995b)

As características básicas do Boundary Layer Radar (BLR) são mostrados na Tabela 1. Este foi projetado para receber ecos de retroespalhamento causados por flutuações no índice refrativo, segundo (Wyngaard e Le Mone, 1980). Três antenas parabólicas são apontadas, sendo uma na vertical e duas em direções oblíquas alinhadas com o leste e com o norte num ângulo zenital de $15^{\circ}$. O BLR fornece perfis verticais das três componentes do vento, parâmetros de turbulência (em dias de céu-claro) e de características de gotas de chuva (em dias chuvosos), na baixa troposfera, inclusive na CLA, com resolução temporal e vertical de cerca de 1 min em $100 \mathrm{~m}$. O BLR foi instalado em PUSPITEK - National Center for Research Science and Techonology, em outubro de 1992 e tem operado continuamente desde 9 de novembro de 1992. Controlado por um computador on-line, a operação do BLR dispensa a intervenção humana, exceto na troca das fitas com dados gravados a cada 4 ou 5 dias. A alta resolução na escala vertical e no tempo observado pelo BLR contribui para melhorar o conhecimento e a interpretação da CLA na região. 
Tabela 1 - Características Básicas do radar Doppler banda-L.

\begin{tabular}{cl}
\multicolumn{1}{c}{ Parâmetros } & \multicolumn{1}{c}{ Valor } \\
\hline Freqüência & $1357,5 \mathrm{MHz}$ (Banda L) \\
Antena & Três antenas parabólicas \\
\hline Abertura & $3,1 \mathrm{~m}^{2}$ (2 m de diâmetro) \\
\hline Largura do feixe & $7,6^{\circ}$ (potência média) \\
\hline Direção do feixe & Fixo nas três direções \\
\hline Transmissor & Três amplificadores Solid State \\
\hline Potência máxima & $1 \mathrm{~kW}$ \\
\hline Potência média & $20 \mathrm{~W}$ \\
\hline Duração de pulso & $0,67,1,0,2,0$ s \\
\hline & Fonte: Hashiguchi .H et al. (1995b).
\end{tabular}

$\mathrm{O}$ vento em superfície (aproximadamente $10 \mathrm{~m}$ do solo) foi monitorado pelo anemômetro OGASAWARA WS-A54, sendo plotados na forma de vetores na parte inferior das figuras relativas à seção tempo-altura dos ventos zonal-meridional, conforme as Figuras 11, 14 e 16. A direção do vetor é para cima, quando o vento for de norte e para a direita quando o vento for de leste. Os dados obtidos pelo piranômetro EKO MS-42, referentes à estação seca foram usados para a quantificação da radiação solar, conforme a Figura 12 (a). Os dados de temperatura do ar à superfície foram obtidos pelo termômetro V̈̈ISÄL $\ddot{A}$ HMP133 Y,, conforme a Figura 12 (b).

\subsection{Dados utilizados}

Foram utilizados os dados de eco de radar (refletividade) e vento, radiossondagem e superfície necessária ao estudo da CLA na região. Assim, foram utilizadas as informações de 64 níveis diferentes, isto é, entre 0,1 e $6,4 \mathrm{~km}$ de altura, para as observações com radar. Os ecos de radar, para cada uma das 64 alturas observadas foram integrados, utilizando informações a cada 3,2 m num intervalo de $100 \mathrm{~m}$, para formar o valor de uma amostra e, posteriormente uma série temporal com 128 amostras. O espectro Doppler com 128 valores foi calculado para cada altura, em aproximadamente $0,4 \mathrm{~s}$, usando a Transformada de Fourier, (Hashiguchi et al., 1995b). A direção do feixe do radar foi mudada imediatamente depois da alteração do espectro Doppler. Finalmente, foram calculadas as médias de 32 espectros Doppler para cada altura, obtendo-se os perfis verticais para as 3 direções num intervalo de tempo de $50 \mathrm{~s}$, e o tempo de transferência dos dados foi de aproximadamente 10 s para o computador.

A medida do vento horizontal foi determinada pelo BLR, da seguinte forma:

$$
\mathrm{V}_{\mathrm{h}}=\frac{\mathrm{V}_{\mathrm{r}}(\theta)-\mathrm{V}_{\mathrm{r}}(-\theta)}{2 \operatorname{sen} \theta}
$$

Onde, $\mathrm{V}_{\mathrm{r}}(\theta)$ e $\mathrm{V}_{\mathrm{r}}(-\theta)$ refere-se as velocidades com os respectivos feixe de inclinação do $\operatorname{radar}(\theta)$, a simbologia usada para $(+)$ ou (-) baseia-se no comportamento da velocidade radial Doppler.

O volume encontrado foi dado pela largura do feixe radar de 7,6 $6^{\circ}$ com resolução vertical de $100 \mathrm{~m}$. A velocidade vertical foi determinada utilizando-se o feixe vertical do radar correspondente ao valor médio para um volume rugoso de $130 \mathrm{~m}$ de largura por $100 \mathrm{~m}$ de espessura para cada $1 \mathrm{~km}$ de altura. As componentes zonal e meridional são os valores correspondentes a um volume de cerca de $400 \mathrm{~m}$ de largura e $100 \mathrm{~m}$ espessura, a cada $1 \mathrm{~km}$ de altura. Supondo que os campos de vento neste volume são homogêneos, as velocidades calculadas podem ser consideradas como valores representativos em um período de amostragem de aproximadamente 1 minuto, embora algumas médias sejam necessárias para que se obtenha valores confiáveis.

\section{RESULTADOS E DISCUSSÃO}

Durante a validação dos resultados foi encontrada dificuldades em relacionar radar-radiossondagem, devido à característica observacional dos dois instrumentos quanto ao seu tempo de resposta. Todavia, conseguiu-se correlacionar os dados de radar (vento) e sondagem atmosférica, devido ao estabelecimento de um intervalo de $100 \mathrm{~m}$ em cada camada, totalizando 64 camadas referentes às observações com radar, no entanto, apenas houve correspondência entre eles até aproximadamente $5 \mathrm{~km}$, no qual corresponde a altura máxima da CLAT, conforme as Figuras 11 e 13.

\subsection{Validação dos dados radar (vento)}

Os dados de radar foram observados a partir de $0,3 \mathrm{~km}$, pois no local do experimento o vento predominante corresponde a esta altura. Analisando-se a Figura 3(a) e (b), correspondente ao horário de entrada da brisa marítima na região, notou-se que existe uma boa correlação da direção e intensidade do vento entre os dados de radar e de radiossondagem, principalmente entre as alturas de 1 a $3 \mathrm{~km}$, através das Figuras 3(c) e (d), onde se obtêm os coeficientes de correlação da ordem 0,91 , em ambos casos, na intensidade e direção do vento. Para restante do período da estação seca, os valores dos coeficientes de correlação variaram entre 0,83 e 0,94 para o respectivo horário, o que não acontece na chuvosa, onde os coeficientes de correlação variaram entre 0,77 a 0,88 (intensidade), essa redução se deve em função dos dias em que a precipitação foi intensa, porém os coeficientes de correlação foram da ordem de 0,3 (direção), conforme a Tabela 2 .

Através da média da diferença, e depois dos respectivos desvios padrão, nota-se que em todos os dias observados na 


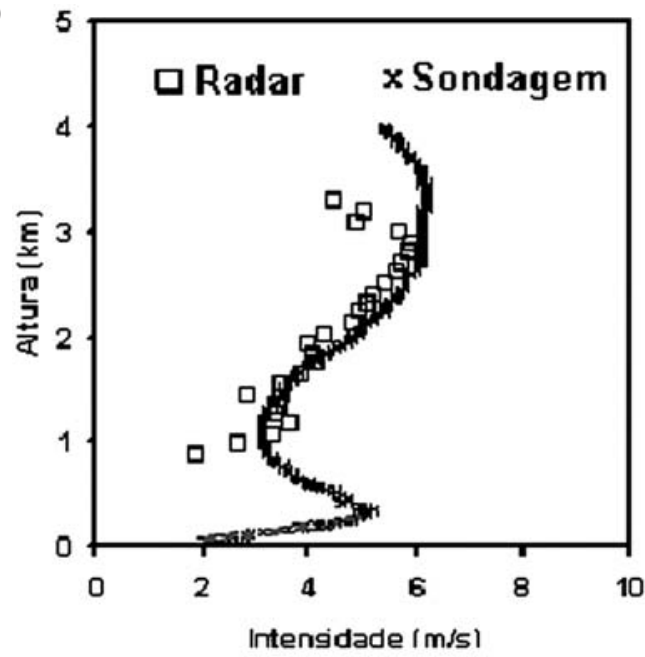

b)

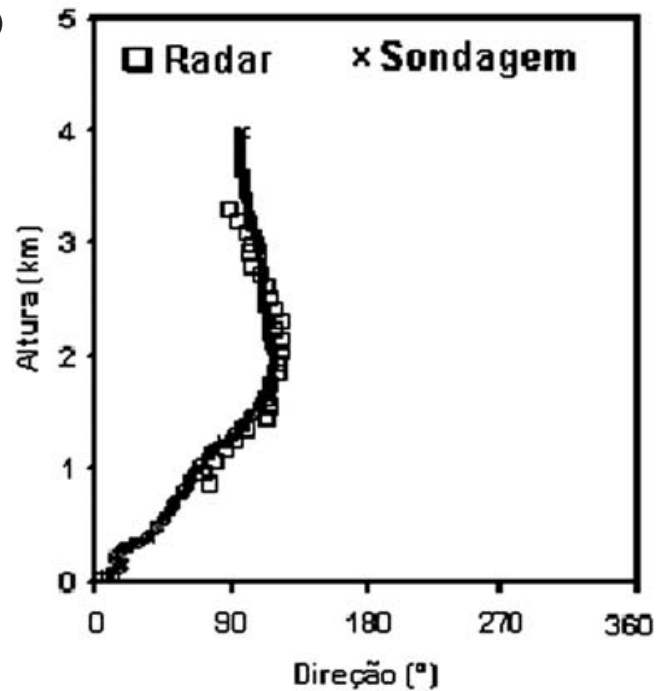

c)

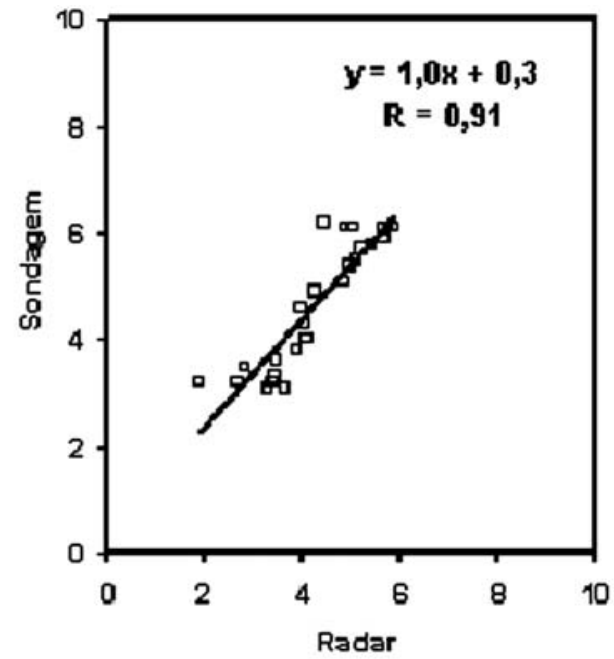

d)

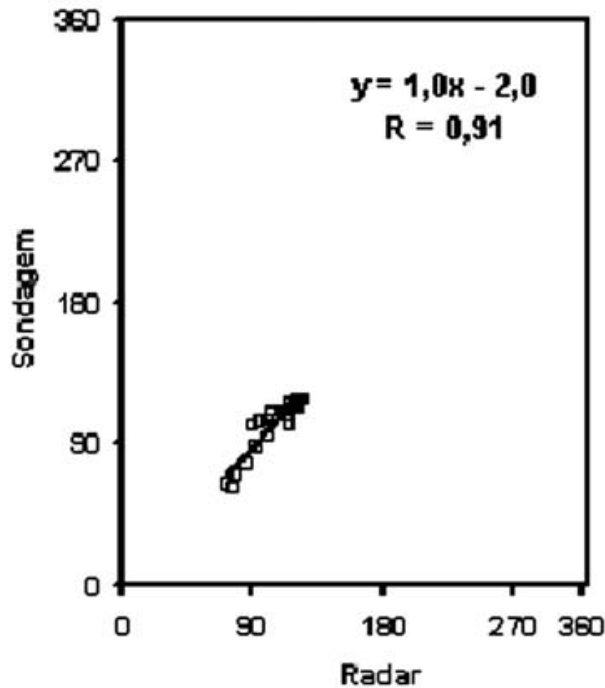

Figura 3 - Comparação da Intensidade (a) e Direção do Vento (b) às 1500 TL através do radar Doppler $(\square)$ e da Radiossondagem $(\times)$ e a regressão da Intensidade (c) e Direção (d) no dia 12/10/1993.

Figura 4(a) na altura entre 1 e $2 \mathrm{~km}$, a velocidade do vento apresentou-se mais intensa, enquanto que na Figura 4(b) ocorreu uma forte região entre 0,3 e $2 \mathrm{~km}$, sendo isso associado ao efeito da brisa marítima que afetou significativamente a velocidade e a direção do vento neste horário durante todo o período. Esta variação em ambos casos (direção e intensidade) foi marcada fortemente pela circulação da brisa marítima, onde foi geralmente caracterizada pelo desenvolvimento do vento na costa próximo a superfície, um fluxo de retorno em altitude e a reversão na direção do vento. Verifica-se na Figura 5(a) e (b) que a circulação da brisa às $1800 \mathrm{TL}$, ocorreu que a intensidade abaixo de $2 \mathrm{~km}$ diminui sensivelmente em comparação às $1500 \mathrm{TL}$, porém a direção teve um aumento significativo em comparação às 1500 TL.
Nota-se Figura 6(a) e (c) às 1800 TL, que há uma diminuição significativa do coeficiente de correlação em comparação às $1500 \mathrm{TL}$, sendo da ordem de 0,77 e para o restante do período sendo da ordem de 0,88 , conforme a Tabela 2 . No caso da direção verifica-se que na Figura 6(b) e (d) não há uma boa correlação entre os dados de radar e radiossondagem, onde o coeficiente de correlação foi da ordem de 0,12 , neste caso e no restante do período da ordem de 0,3 . Acreditamos que isso se deve ao problema de correlacionar os dados em função do ângulo meteorológico $\left(0^{\circ}\right.$ confunde-se com $360^{\circ}$, direção norte), para solucionar o problema, o ângulo visto pelo radar foi convertido em ângulo trigonométrico (gráfico), no intuito de identificar as mudanças da direção do vento nas estações em relação a estes respectivos horários. 

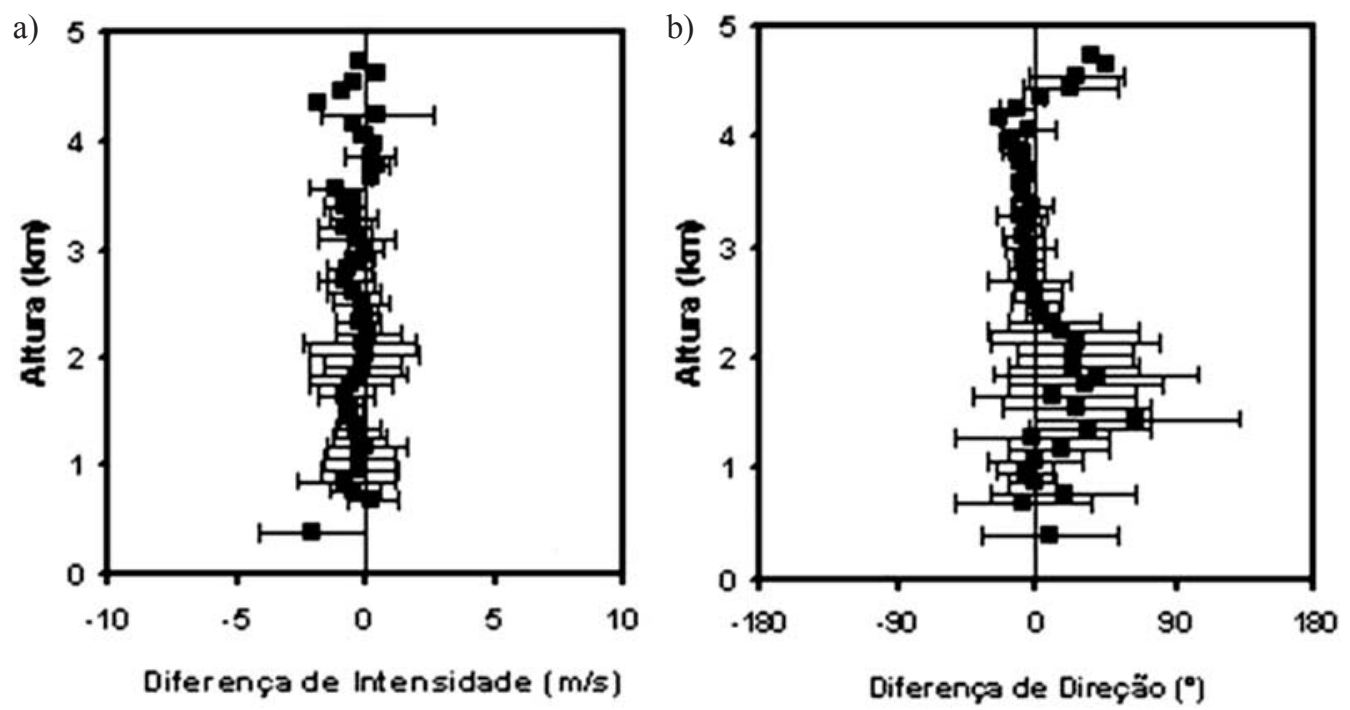

Figura 4 - Desvios Padrão da Intensidade (a) e Direção do Vento (b) através da diferença radar Doppler e Radiossondagem às 1500 TL no período de 08 - 14/10/1993.
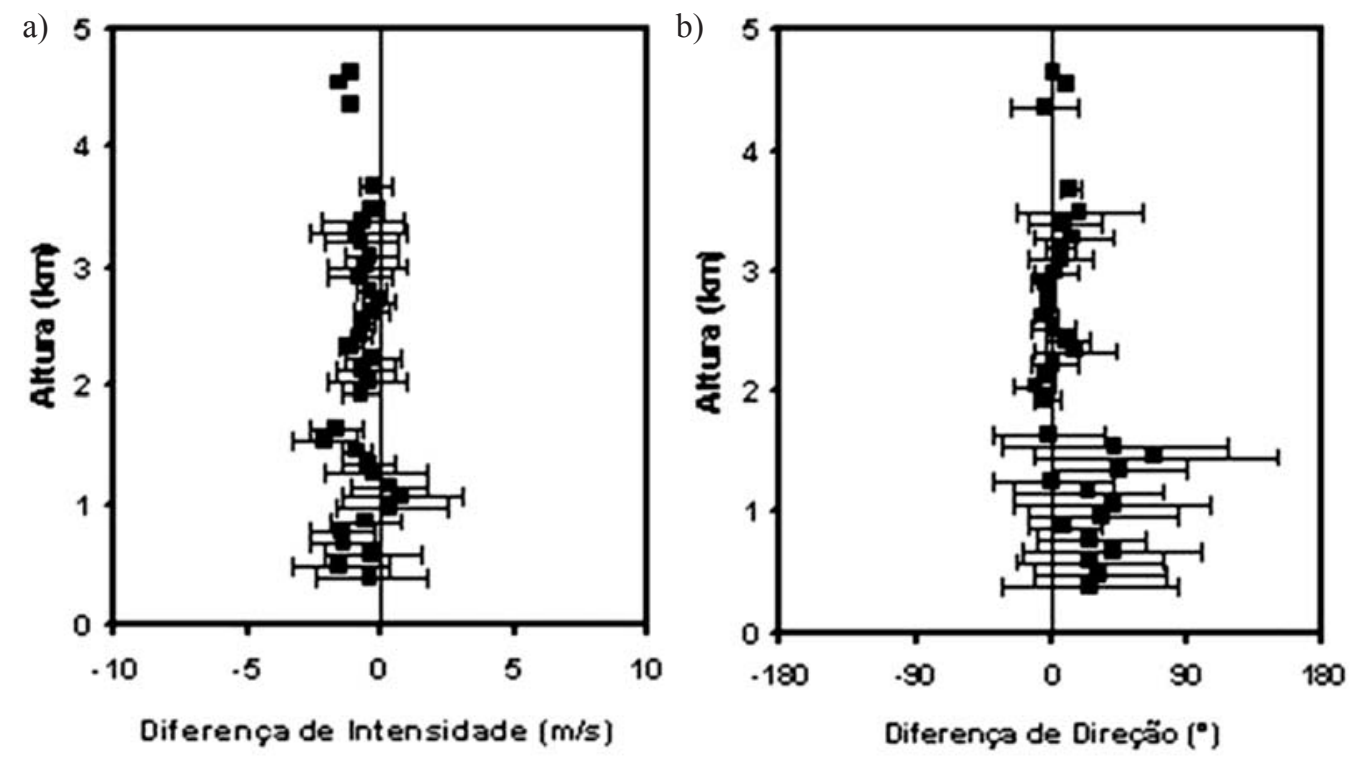

Figura 5 - Desvios Padrão da Intensidade (a) e Direção do Vento (b) através da diferença radar Doppler e Radiossondagem às 1800 TL no período de 09 - 13/10/1993.

A partir disso, foi feito à decomposição vetorial das componentes, u e v, e $\alpha$ é o ângulo meteorológico obtido através da decomposição da componente horizontal do vento e $\xi$ é o ângulo trigonométrico observado pelo radar, dado por:

$$
\xi=270^{\circ}-\alpha, \quad \alpha=\arctan \left(\frac{\mathrm{v}}{\mathrm{u}}\right) .
$$

Um algoritmo matemático foi criado para fazer a distinção entre a diferença da direção observada pelo radar e a radiossonda a cada $180^{\circ}$, onde são consideradas duas situações:

$$
\begin{aligned}
& \mathrm{D}_{\mathrm{R}}-\mathrm{D}_{\mathrm{s}}>180^{\circ} \\
& \mathrm{D}_{\mathrm{RC}}=360-\mathrm{D}_{\mathrm{R}}
\end{aligned}
$$

Onde, $D_{R}\left[{ }^{\circ}\right]$ é a direção observada pelo radar, $D_{S}\left[{ }^{\circ}\right]$ é a direção observada pela radiossonda e $D_{R C}\left[{ }^{\circ}\right]$ é a diferença do ângulo de $360^{\circ}$ e a direção observada pelo radar.

$$
\begin{aligned}
& \mathrm{D}_{\mathrm{R}}-\mathrm{D}_{\mathrm{s}}<180^{\circ} \\
& \mathrm{D}_{\mathrm{SC}}=360-\mathrm{D}_{\mathrm{S}}
\end{aligned}
$$


a)

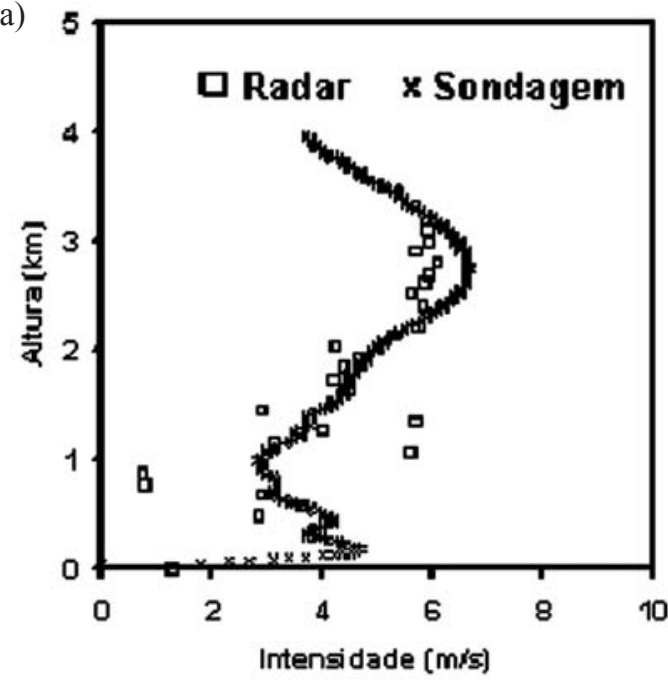

b)

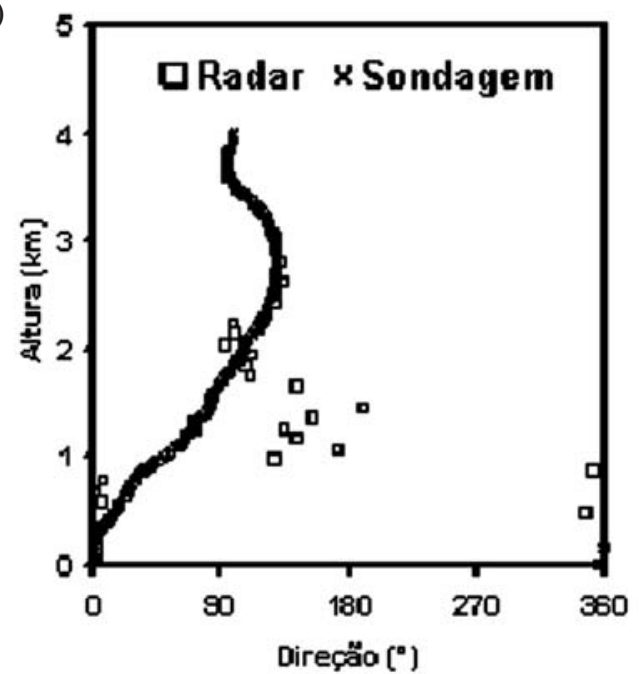

c)

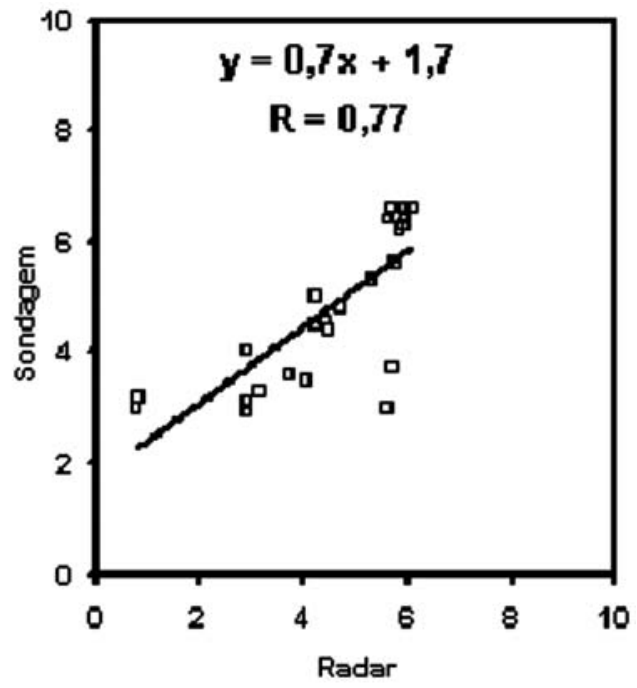

d)

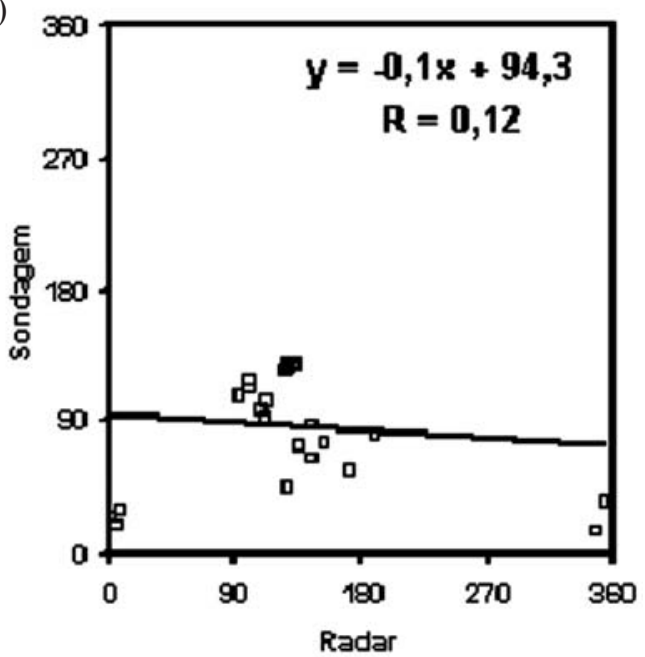

Figura 6 - Comparação da Intensidade (a) e Direção do Vento (b) às 1800 TL através do radar Doppler ( $\square$ ) e da Radiossondagem (×) e a regressão da Intensidade (c) e Direção (d) no dia 12/10/1993.

Onde, $D_{R}\left[^{\circ}\right]$ é a direção observada pelo radar, $D_{S}\left[^{\circ}\right]$ é a direção observada pela radiossonda e $D_{S C}\left[{ }^{\circ}\right]$ é a diferença do ângulo de $360^{\circ}$ e a direção observada pela radiossonda.

Foram feitas algumas análises e comparações em relação às variações diurna e noturna na direção e velocidade do vento, principalmente nos horários de 1500 e 1800 TL, pois estes horários apresentaram discrepâncias em relação aos índices de correlações, para os outros horários tiveram os resultados semelhantes, conforme a Tabela 2. Nota-se que após a correção realizada pelo algoritmo para estes respectivos horários, houve um ganho significativo no coeficiente da direção e intensidade do vento para os dias 11, 12 e 13/10/1993, na estação seca, conforme a Tabela 2 (a). Na chuvosa, verificou-se um ganho significativo no coeficiente da direção e intensidade do vento para os dias 16, 18, 20 e 21/02/1994, conforme a Tabela 2 (b).

Em relação ao comportamento diurno a intensidade e a direção do vento possui um regime não variável, onde os índices de correlações variaram entre 0,5 a 0,75 , na estação seca, enquanto que no período noturno ocorre uma diminuição significativa. Na chuvosa, quando a precipitação não foi muito intensa, persistiu a característica da estação seca, onde os melhores índices de correlações foram nos horários de 1500 e 1800 TL, quando a chuva foi muito intensa, os índices de correlações variaram entre 0,77 a 0,88 , durante todo período, porém os índices de correlações para direção tiveram uma diminuição significativa, em comparação à estação seca. 
Tabela 2 - Comparações entre os coeficientes de correlações do radar Doppler banda -L e radiossoda Väisälä-RS80 nas estações seca (a) e chuvosa (b), nos respectivos horários 1500 e $1800 \mathrm{TL}$.

(a)

\begin{tabular}{cccc}
\hline \multirow{2}{*}{ Período } & Horário & \multicolumn{2}{c}{$\begin{array}{c}\text { Estação Seca } \\
\text { (Coeficiente de Correlação) }\end{array}$} \\
\cline { 3 - 4 } & & Direção & Intensidade \\
\hline $09 / 10 / 1993$ & $1500 \mathrm{TL}$ & 0,14 & 0,38 \\
\hline $09 / 10 / 1993$ & $1800 \mathrm{TL}$ & 0,15 & $\mathbf{0 , 8 8}$ \\
\hline $10 / 10 / 1993$ & $1500 \mathrm{TL}$ & $\mathbf{0 , 5 3}$ & 0,22 \\
\hline $10 / 10 / 1993$ & $1800 \mathrm{TL}$ & $\mathbf{0 , 8 0}$ & 0,43 \\
\hline $11 / 10 / 1993$ & $1500 \mathrm{TL}$ & 0,07 & $\mathbf{0 , 9 1}$ \\
\hline $11 / 10 / 1993$ & $1800 \mathrm{TL}$ & 0,40 & $\mathbf{0 , 7 1}$ \\
\hline $12 / 10 / 1993$ & $1500 \mathrm{TL}$ & $\mathbf{0 , 9 1}$ & $\mathbf{0 , 9 1}$ \\
\hline $12 / 10 / 1993$ & $1800 \mathrm{TL}$ & 0,01 & $\mathbf{0 , 7 7}$ \\
\hline $13 / 10 / 1993$ & $1500 \mathrm{TL}$ & $\mathbf{0 , 6 6}$ & 0,34 \\
\hline $13 / 10 / 1993$ & $1800 \mathrm{TL}$ & $\mathbf{0 , 9 2}$ & 0,31 \\
\hline $14 / 10 / 1993$ & $1500 \mathrm{TL}$ & 0,06 & 0,04 \\
\hline $14 / 10 / 1993$ & $1800 \mathrm{TL}$ & 0,003 & 0,004 \\
\hline
\end{tabular}

\subsection{Validação dos dados radar (eco de radar)}

A partir, dos perfis típicos de temperatura potencial $\theta(\mathrm{K})$ e umidade específica q ( $\mathrm{g} / \mathrm{kg}$ ) pode-se estimar a altura da CLAT e validar com os dados de eco de radar. Os dados de eco de radar e os respectivos perfis forneceram a evolução diária da CLAT para toda a estação seca. No entanto, optou-se pela escolha do dia 12/10/1993, pois este apresentava uma situação típica de circulação de brisa marítima na região. Para $\theta$ e q mostrou-se na Figura 7(a) que abaixo de 0,6 km houve a formação de um gradiente superadiabático. A CLAT iniciou-se às 0900 TL com uma altura de $1 \mathrm{~km}$ e continuou ascendendo através da forçante superficial até $2 \mathrm{~km}$ de altura às $1200 \mathrm{TL}$, enquanto que às 1500 TL não há uma boa identificação quanto à altura da CLAT, visto que nesta hora, ocorreu uma maior influencia da circulação da brisa marítima que quebrou o desenvolvimento da CLAT e da ocorrência de nebulosidade neste respectivo horário, sendo confirmado pela Figura 12 (a).

Mostrou-se a típica evolução da CLAT na Figura 8, através dos picos de eco de radar na estimativa da altura da CLAT. Notou-se que há uma semelhança entre os picos de gradientes verticais de temperatura e umidade observados pelo BLR e os perfis de $\theta$ e q. Às $0900 \mathrm{TL}$, o pico máximo apareceu próximo a $1 \mathrm{~km}$, sendo identificado nos perfis de $\theta$ e q. Ocorreu um aumento da CLAT às 1200 TL atingindo aproximadamente $2 \mathrm{~km}$ de altura. Para o intervalo entre 0900 TL às 1200 TL existiram diferenças na altura da CLAT, em relação aos picos e os perfis de (b)

\begin{tabular}{cccc}
\hline \multirow{2}{*}{ Período } & Horário & \multicolumn{2}{c}{$\begin{array}{c}\text { Estação Chuvosa } \\
\text { (Coeficiente de Correlação) }\end{array}$} \\
\cline { 2 - 4 } & & Direção & Intensidade \\
\hline $16 / 02 / 1994$ & $1500 \mathrm{TL}$ & 0,40 & $\mathbf{0 , 9 0}$ \\
\hline $16 / 02 / 1994$ & $1800 \mathrm{TL}$ & $\mathbf{0 , 6 6}$ & $\mathbf{0 , 9 1}$ \\
\hline $17 / 02 / 1994$ & $1500 \mathrm{TL}$ & 0 & 0 \\
\hline $17 / 02 / 1994$ & $1800 \mathrm{TL}$ & 0,05 & 0,34 \\
\hline $18 / 02 / 1994$ & $1500 \mathrm{TL}$ & $\mathbf{0 , 5 8}$ & $\mathbf{0 , 6 7}$ \\
\hline $18 / 02 / 1994$ & $1800 \mathrm{TL}$ & $\mathbf{0 , 9 8}$ & $\mathbf{0 , 8 2}$ \\
\hline $19 / 02 / 1994$ & $1500 \mathrm{TL}$ & 0,01 & 0,04 \\
\hline $19 / 02 / 1994$ & $1800 \mathrm{TL}$ & 0,09 & 0,41 \\
\hline $20 / 02 / 1994$ & $1500 \mathrm{TL}$ & 0,16 & 0,43 \\
\hline $20 / 02 / 1994$ & $1800 \mathrm{TL}$ & $\mathbf{0 , 8 2}$ & $\mathbf{0 , 6 0}$ \\
\hline $21 / 02 / 1994$ & $1500 \mathrm{TL}$ & $\mathbf{0 , 7 0}$ & $\mathbf{0 , 9 1}$ \\
\hline $21 / 02 / 1994$ & $1800 \mathrm{TL}$ & 0,44 & $\mathbf{0 , 7 0}$ \\
\hline
\end{tabular}

sondagem, isso se deve à interpolação entre a radiossondagem, que realiza sua medida a cada 3 horas e o BLR a cada 1 hora. Já, às 1500 TL há uma concordância entre os perfis de $\theta$ e q e os picos do eco de radar na identificação da altura da CLAT, uma vez que entre 1 e $2 \mathrm{~km}$ de altura, não há um forte gradiente da potência do eco de radar, conforme a Figura 8.

Notou-se uma diminuição do gradiente de temperatura entre as 1500 e 1800 TL, bem como no perfil típico de q, conforme as Figuras 7(c) e 9(a). Todavia, às 1800 TL apresenta uma altura máxima de $1 \mathrm{~km}$, conforme a Figura 9(a), no entanto o pico do gradiente do eco de radar apresentou-se fraco para este horário, atribui-se aos buracos causados pela refletividade atmosférica, conforme a Figura 8. Às 2100 TL, inicia-se a CLR (Camada Limite Residual), Figura 9(b), exceto próximo das $2400 \mathrm{TL}$, onde existiu uma região próxima de $2,5 \mathrm{~km}$, onde se identificou uma grande variação do gradiente do eco de radar em comparação a Figura 9(c). No intervalo de 1800 às 2400 TL ocorreu o decréscimo em dBz (-35 e -40), isso se deve a umidade que foi evaporada na CM e ficou retida na CLR afetando o poder de eco do radar.

\subsection{Variação da CLAT (estação seca)}

Pela manhã, na estação seca próximo das 0900 TL em todo período de estudo encontrou-se uma camada de eco significativa (1) que aparecia no local do experimento $(0,3 \mathrm{~km})$, e gradualmente ascendia até 3-5 km de altura próximo das 1600 TL. Esta 


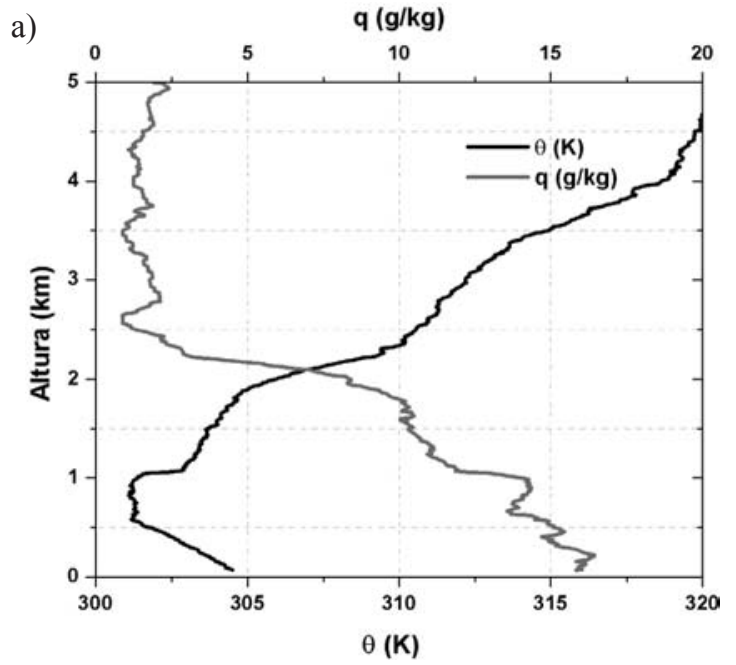

b)

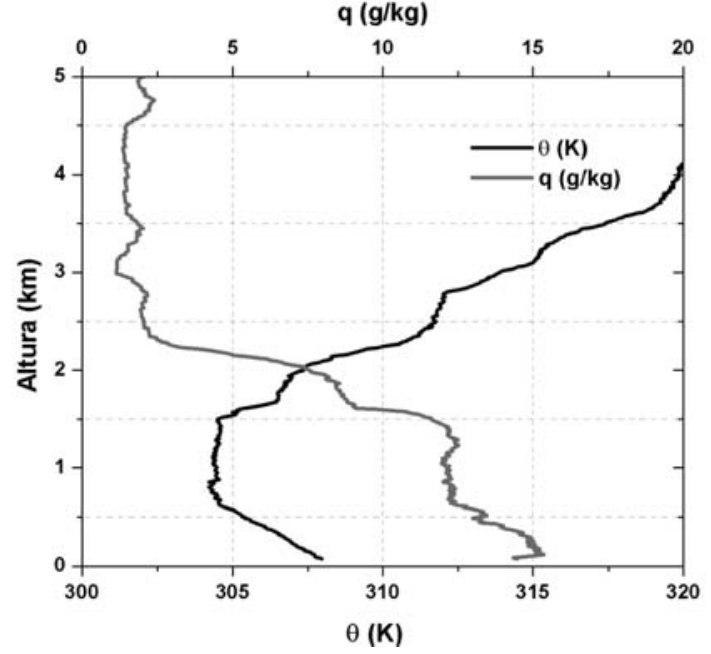

c)

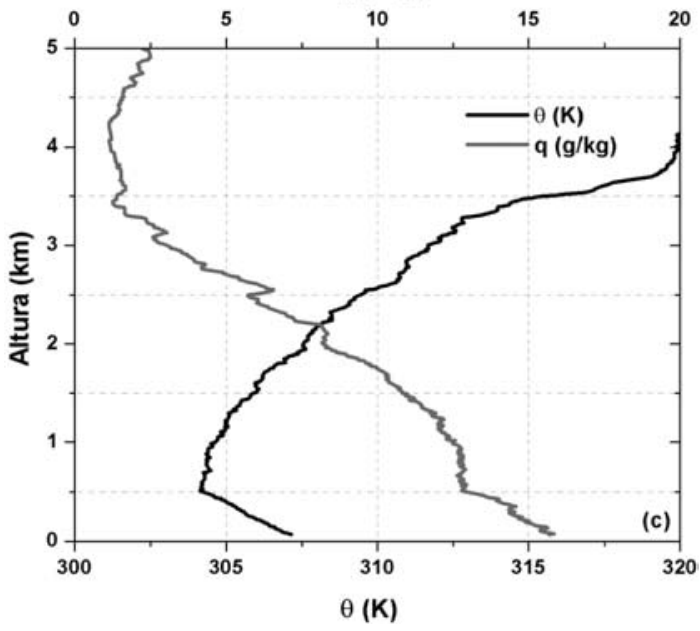

Figura 7 - Perfil da Temperatura Potencial Virtual $\left(\theta_{v}\right)$ e Umidade Específica $(\boldsymbol{q})$ para os respectivos horários 0900 TL (a), 1200 TL (b) e 1500 TL (c) no dia do 12/10/1993.

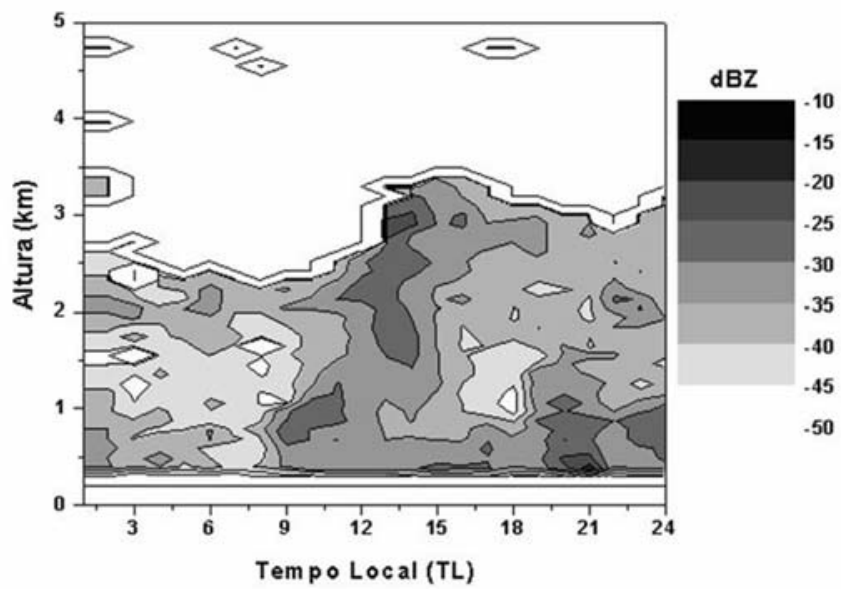

Figura 8 - Seção transversal tempo-altura do fator equivalente de refletividade radar observado com o BLR, em Serpong, no dia 12 de Outubro de 1993. 
a)

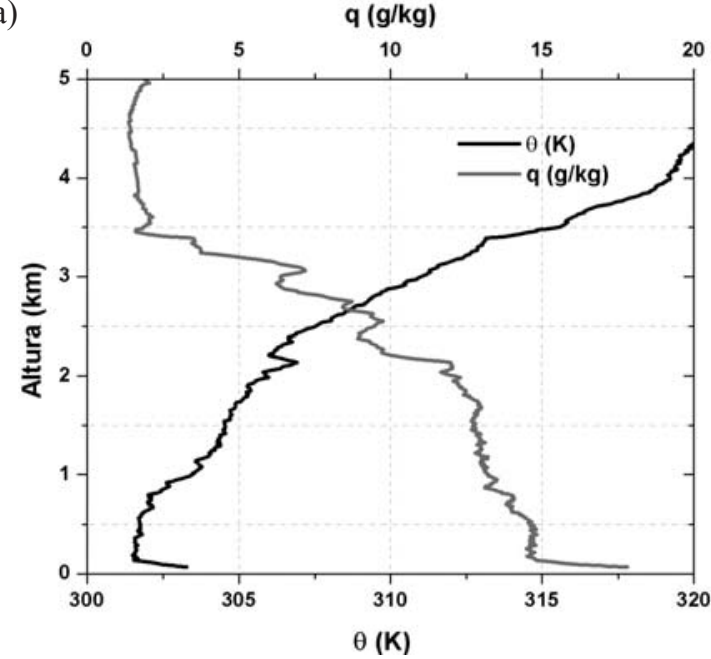

b)

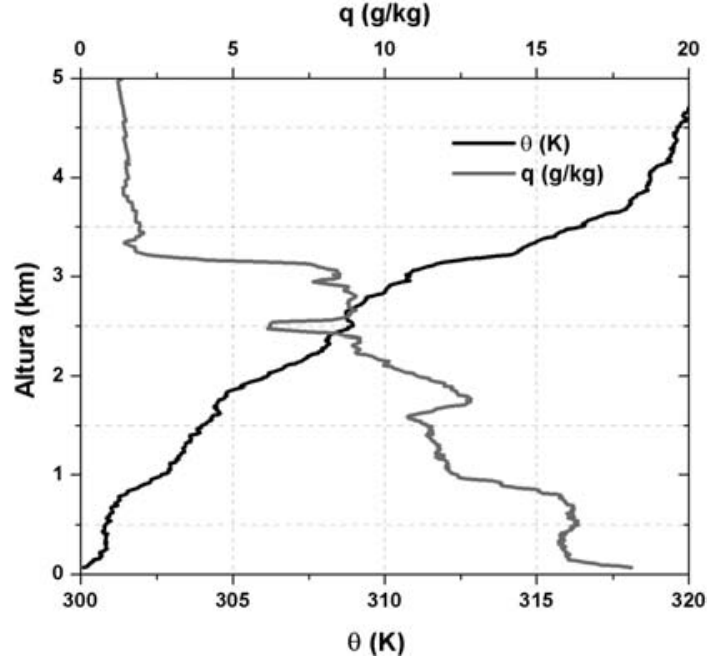

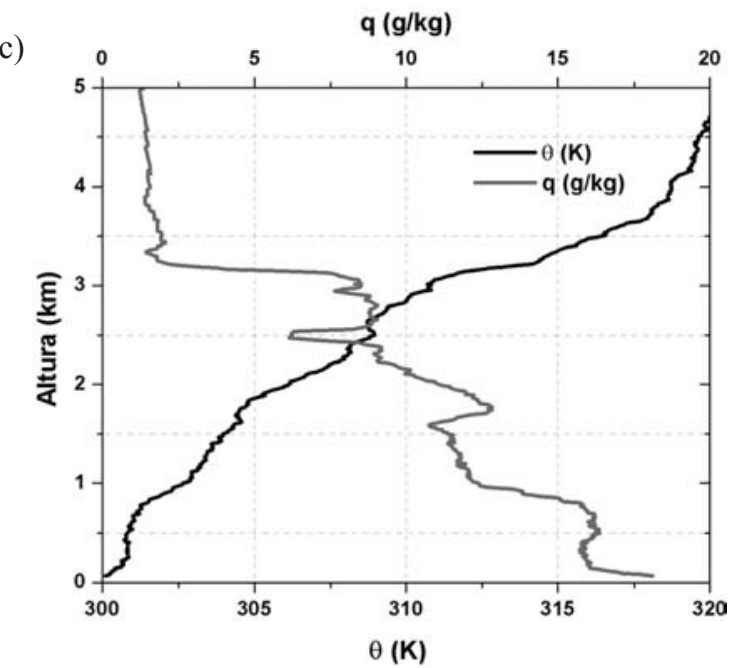

Figura 9 - Perfil da Temperatura Potencial Virtual $\left(\theta_{v}\right)$ e Umidade Específica $(\boldsymbol{q})$ para os respectivos horários 1800 TL (a), 2100 TL (b) e 2400 TL (c) no dia do 12/10/1993.

estrutura foi menos pronunciada à noite, onde se identificou o topo da CLR. O segundo tipo de camada de eco (2) foi observado entre 2-3 km de altura, durante as 2000-2400 TL e descendo para cerca de $0,3 \mathrm{~km}$ próximo das $0600 \mathrm{TL}$ todas às manhãs. Para estes três dias foram observadas variações diurnas na intensidade da potência dos ecos de radar típicos de dias claros, onde a nebulosidade não foi tão intensa. Observações em outros dias claros (8-9 e 13-15/10/1993) mostraram-se variações diurnas semelhantes, mas em dias nublados essas características eram fracas ou mesmo ausentes. Foram observados "buracos" no pico do gradiente de umidade que resultaram em ecos fracos.

Notou-se na Figura 11, variações nas duas componentes do vento observadas com o BLR. Identificou-se que a direção e intensidade do vento mudaram drasticamente próximo de $0,3 \mathrm{~km}$ durante o dia e entre $3-5 \mathrm{~km}$ de altura à noite. Abaixo da $\mathrm{CM}$, o vento horizontal foi geralmente fraco e muito variável. As componentes horizontais do vento foram variáveis à noite, embora as flutuações (mudança do regime de vento), fossem relativamente mais fracas que as ocorridas durante o dia. Acima das respectivas camadas, os ventos de leste predominaram durante todo o período de estudo. Apesar das variações no vento de superfície ser menos intensa que observado pelo BLR, o vento em superfície tem direção predominante de norte ou sul, durante o dia, ao longo do período de estudo. Acreditamos que as variações dos ventos em superfície correspondem à circulação de brisa marítima, devido à localização do experimento. 


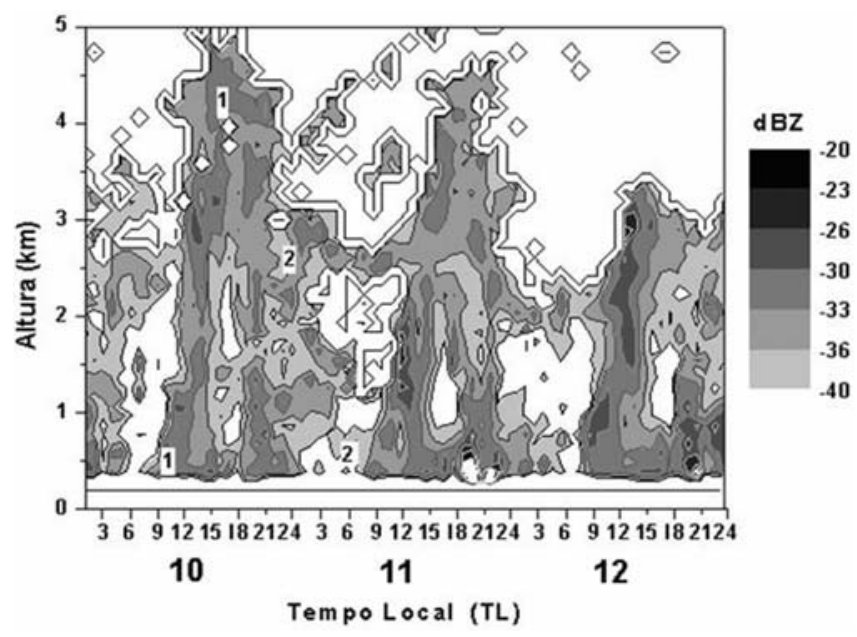

Figura 10 - Média horária das observações no sentido leste, em Serpong, no período de 10-12 de Outubro de 1993. Seção transversal tempo-altura do fator equivalente de refletividade radar observado com o BLR.

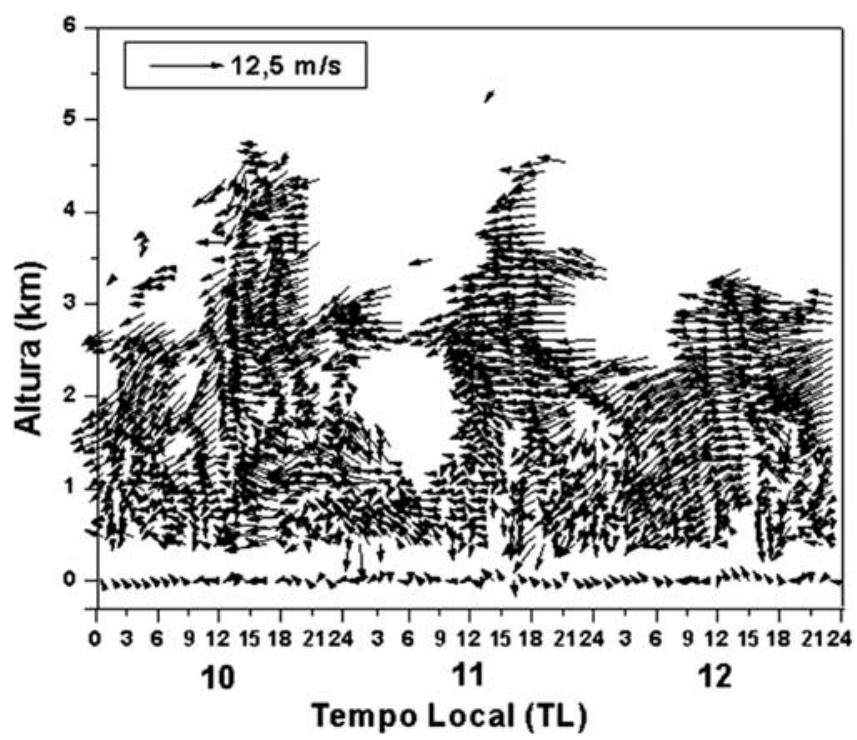

Figura 11 - Médias horárias das observações do BLR, em Serpong, durante o período 10-12 de Outubro de 1993. Seção transversal tempo-altura dos ventos zonal-meridional.

A partir, dos dados de radiação solar global e líquida verificou-se que depois do amanhecer próximo das 0600 TL a radiação solar aumentou rapidamente até as 1200 TL, conforme a Figura 12(a). Notou-se que a nebulosidade foi muito baixa nesse período. Nas tardes do dia 11 e 12/10/93, as nuvens apareceram, freqüentemente no período de 1200-1400 TL. No dia 12/10/93, observou-se que ocorreram as maiores nebulosidades no local do experimento no período de 14001600 TL, embora tal diferença não esteja clara no pico do eco de radar e nas variações do vetor vento. As variações nos dados de temperatura do ar à superfície foram consistentes com as de radiação (ou nebulosidade) e mostraram-se características típicas diurnas num dia céu-claro (máximo depois de meiodia local e mínimo antes de amanhecer local), conforme a Figura 12(b).
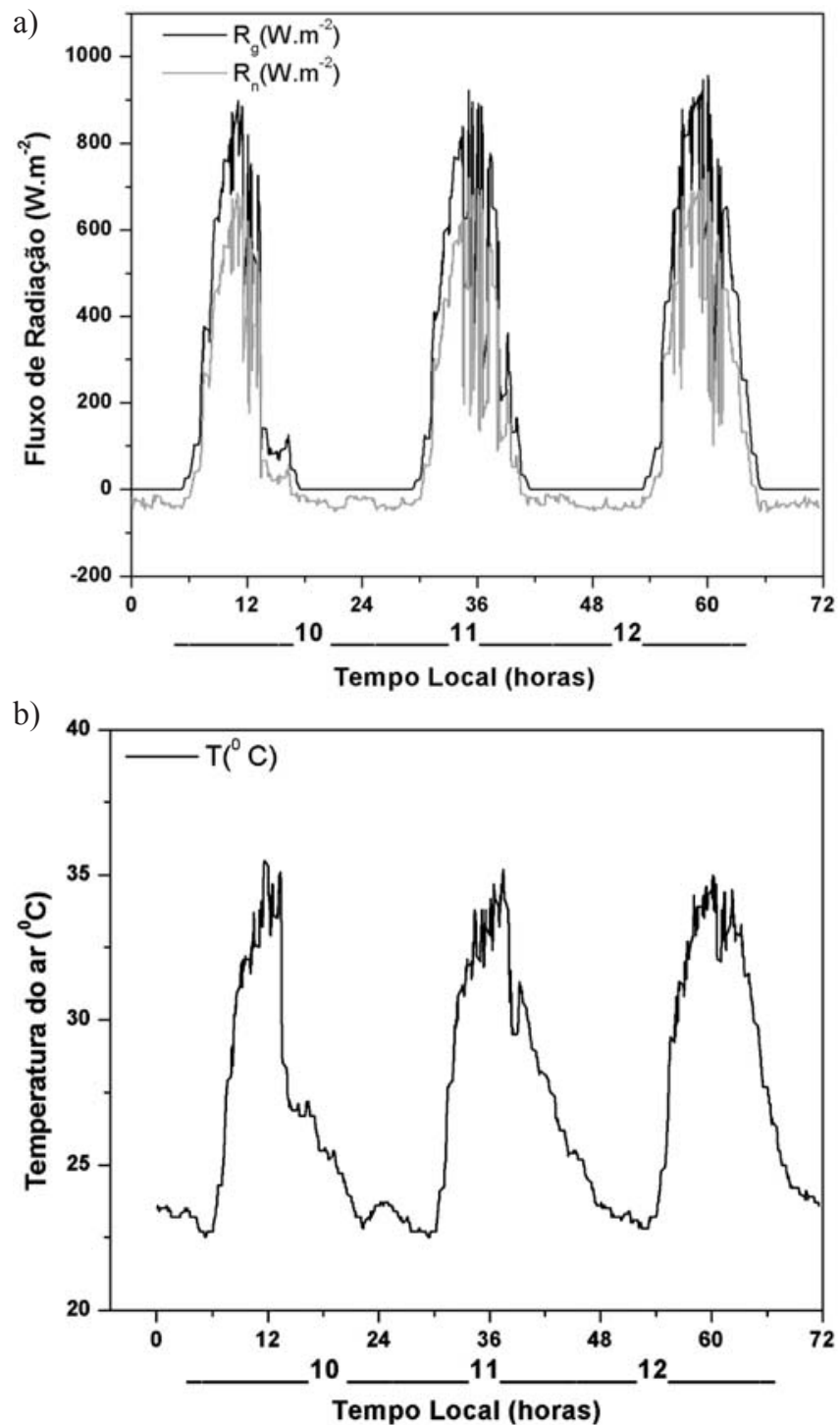

Figura 12 - Variação Temporal da Radiação Solar Global e Radiação Líquida (a) e da Temperatura do ar (b) no local do experimento do radar durante o período de 10-12 de Outubro de 1993.

\subsection{Variação da CLAT (estação chuvosa)}

$\mathrm{Na}$ estação chuvosa observa-se que os dias 20 e 21/02/1994, respectivamente. Às $0600 \mathrm{TL}$ a CM iniciou o seu desenvolvimento alcançando uma altura de aproximada- 
mente $1,5 \mathrm{~km}$ às $1500 \mathrm{TL}$ no 20/02/1994, conforme a Figura 13. A altura máxima da $\mathrm{CM}$ foi mais baixa do que na seca. Não foi possível detectar ecos fortes acima de $1 \mathrm{~km}$, durante o período diurno de 21/02/1994. Após o pôr-do-sol um outro eco forte foi observado sistematicamente, devido às falhas na umidade. De acordo, com perfis de $\theta$ semelhante a camada de eco apareceu próxima a $\mathrm{CM}$, definida por um $\theta$ praticamente constante. Considerando-se os mecanismos de formação de eco de ondas de rádio, supõe-se que a turbulência e a forte flutuação na componente vertical do vento estavam intensificando-se dentro da CM. A falha distinta nas distribuições verticais de umidade e temperatura também contribui para gerar uma forte camada de eco observada pelo BLR. Em dias chuvosos, surgiram ecos fortes causados pela precipitação, mas estes têm um comportamento típico totalmente distinto dos ecos em céu-claro.

Notou-se na Figura 14, que a direção e a velocidade do vento não foram afetados pela brisa marítima. Logo, os alísios durante estes dois dias foram mais fortes do que na estação seca, onde este vento de leste não produziu nenhum cisalhamento que pudesse causar o desenvolvimento da $\mathrm{CM}$. Em conseqüência, a CM não pode se desenvolver na estação chuvosa, já que os fluxos de calor foram fracos e a turbulência mecânica ausente.

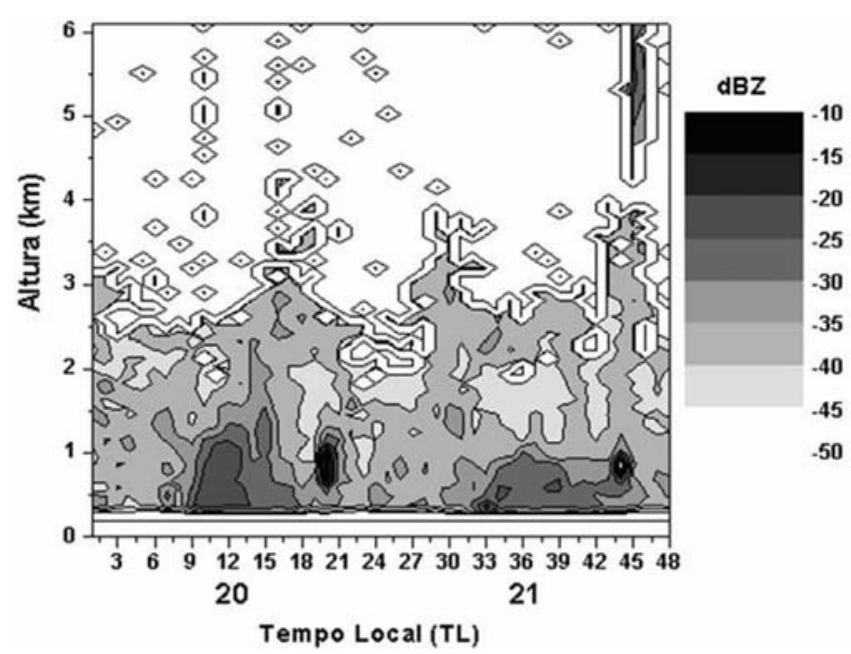

Figura 13 - Média horária das observações no sentido leste, em Serpong, durante o período de 20-21 de Fevereiro de 1994. Seção transversal tempo-altura do fator equivalente de refletividade radar observado com o BLR.
Analisou-se o período seco e o chuvoso através da potência do eco de radar, vetor vento e os perfis de $\theta$ e q, efetuaram-se comparações da sua altura através dos desvios padrão, conforme a Figura 15. Comparando-se as Figuras 15 (a) e 7 (a,b e c), verificou-se que há um aumento da CLAT, a partir das 0900 TL, isso se deve ao aumento da quantidade de radiação solar e atingindo seu pico máximo às $1200 \mathrm{TL}$ (aproximadamente 1,5 km), isto para os dados de radiossondagem. Mas, os dados de eco de radar nesta altura foram bem superiores, isso se deve à variação entre o tempo de medida dos dois instrumentos (radar e radiossonda), mencionado anteriormente. Já, às 1500 TL, notou-se uma diminuição da altura da CLAT, devido ao efeito da brisa marítima, uma vez que se não houvesse esse efeito a altura aumentaria consideravelmente.Para o período chuvoso, conforme a Figura 14(b) há um decréscimo da altura da CLAT nos horários analisados. Particularmente, às $0900 \mathrm{TL}$ diminuiu sensivelmente, o que implica na existência de uma forte dependência da evolução da CLAT em relação a forçante radiativa. Às $1500 \mathrm{TL}$, observa-se que existe um aumento da altura da CLAT, isso se deve à diminuição da brisa marítima, da estação seca para chuvosa. A importância de se avaliar à extensão vertical e as variações diurnas da CLAT, na região de estudo, resultaram em uma evidência observacional com respeito a sua altura mostrando-se claramente estruturas distintas entre a estação seca e chuvosa.

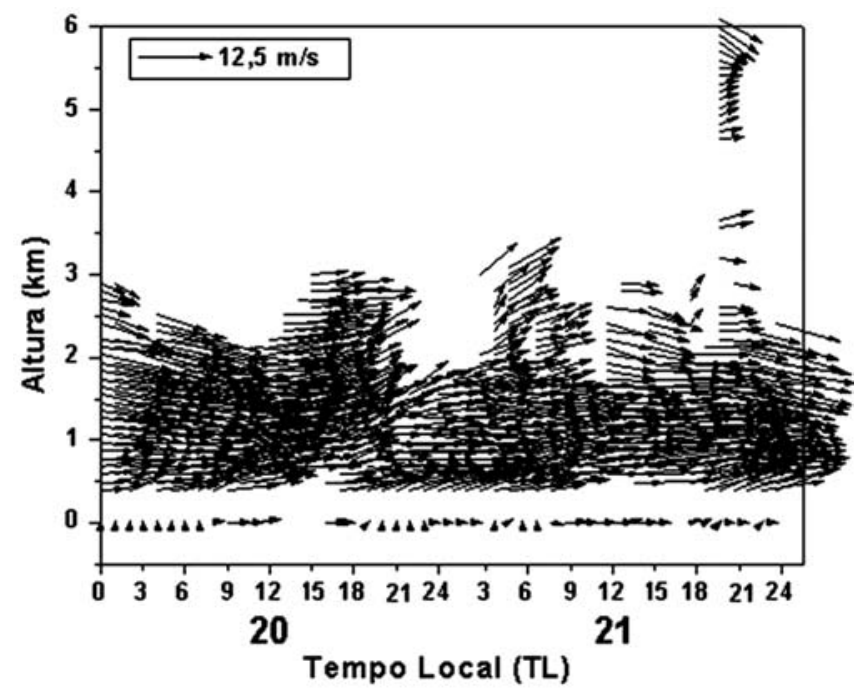

Figura 14 - Médias horárias das observações do BLR, em Serpong, durante o período de 20-21 de Fevereiro de 1994. Seção transversal tempo-altura dos ventos zonal-meridional. 

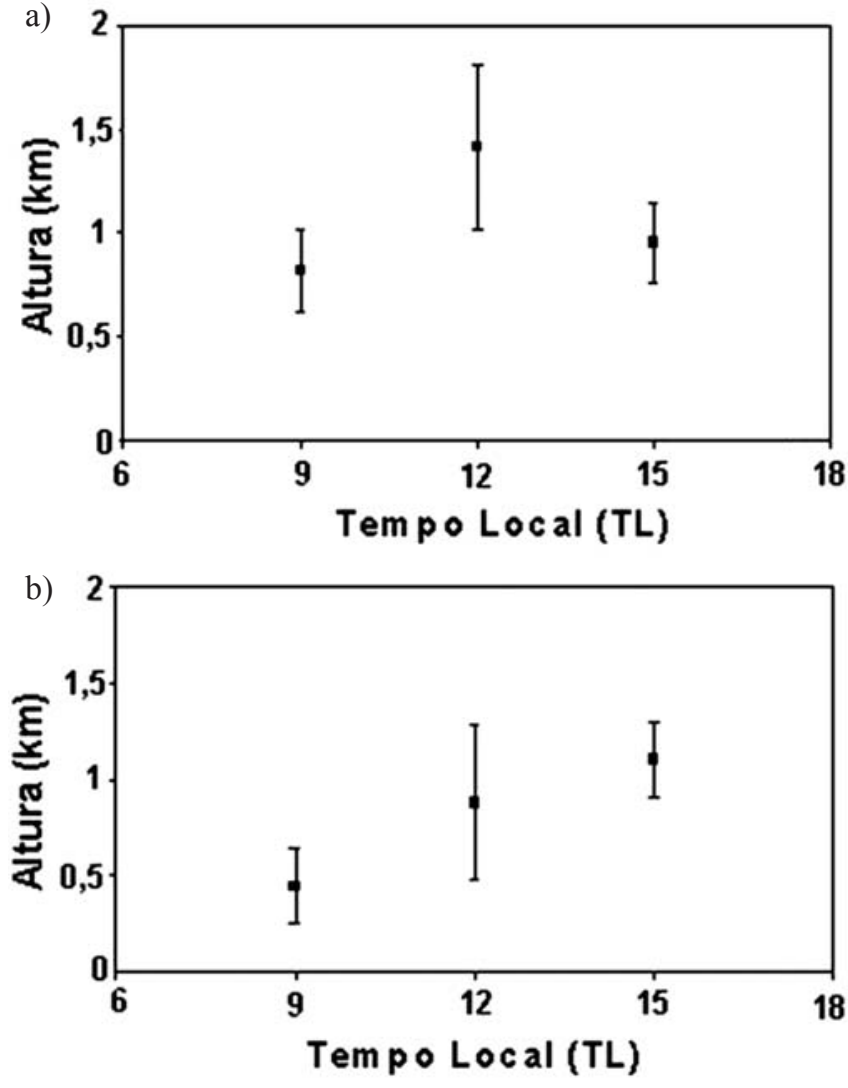

Figura 15 - Desvios Padrão das alturas da CLAT em relação ao horário de medidas para o período seco (09-15 de Outubro de 1993) (a) e o chuvoso (16-21 de Fevereiro de 1994) (b).

\subsection{Efeito da circulação da brisa marítima}

Para um estudo de caso, foi escolhido o dia 12/10/1993, por ter sido constatado como um dia típico de circulação da brisa marítima influenciando a estrutura da CLAT.

A profundidade da CLAT é devida a forçante térmica e mecânica- cisalhamento do vento, onde neste dia o cisalhamento foi forte e o dia foi considerado típico, portanto com as características de insolação e forte aquecimento, deveríamos ter uma CLAT mais profunda, devido à brisa marítima ela foi mínima em função do desenvolvimento de nuvens, depois da sua entrada. $\mathrm{O}$ tempo exato da entrada da brisa marítima varia conforme a sua magnitude e direção do vento predominante, conforme a Figura 16. Em superfície, os dados do BLR foram uma boa estimativa do tempo de entrada da brisa marítima na estação seca, especialmente em dias de céu-claro, quando a umidade no interior da CLAT foi controlada pela circulação da brisa marítima.

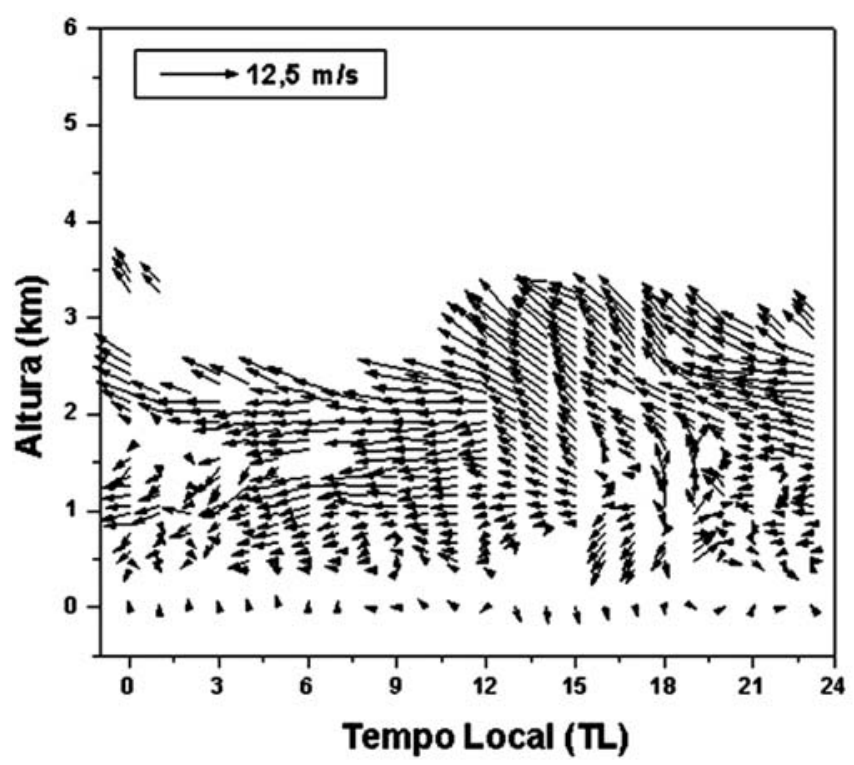

Figura 16 - Seção transversal tempo-altura dos ventos zonalmeridional. Médias horárias das observações do BLR, em Serpong, do dia 12 de Outubro de 1993.

Foi mencionado que às 1500 TL houve a variação em superfície e sendo observada pelos dado de eco de radar, no intuito de detalhar o tempo de entrada da brisa marítima. Verificou-se na Figura 16, que o vento dominante de norte (brisa-mar) começou a fluir ao redor de 1300 TL e seguiu o seu desenvolvimento de vento de norte (fluxo de retorno) sobre $1,5 \mathrm{~km}$ formando a circulação completa, em aproximadamente $1500 \mathrm{TL}$ com uma zona de cisalhamento entre este período. Notou-se que houve uma tendência crescente na profundidade da camada da brisa marítima, no intervalo de 1500 às $1800 \mathrm{TL}$, sendo marcada através da rugosidade zero no cisalhamento do vento.

A profundidade do fluxo da brisa marítima cresceu de $0,8 \mathrm{~km}$ às $1500 \mathrm{TL}$, para $1,5 \mathrm{~km}$ às $1800 \mathrm{TL}$, sendo indicado através do cisalhamento nulo, conforme a Figura 16. Pouco abaixo de $1 \mathrm{~km}$, o gradiente vertical do vento meridional muda de sinal, porque a velocidade horizontal foi desaparecendo próxima a superfície. Exceto ao solo, onde vento zonal foi dominado pelo fluxo vindo de leste e da circulação monçônica, o qual não há nenhuma variação drástica, conforme a Figura 16. Deveria haver um período de transição com variações de pequenas escalas entre 1200-1500 TL, quando da entrada da brisa marítima e do seu encontro com a Camada de Mistura Convectiva (CMC).

Uma variação do vento, caracterizado por padrão aleatório, foi observada antes das $1300 \mathrm{TL}$ indicando que CLAT foi dominada pela atividade convectiva. $\mathrm{O}$ padrão de velocidade horizontal identificado, provavelmente foi inteiramente difundido na CLAT, devido aos grandes movimentos verticais na CM desenvolvida. 


\section{CONCLUSÕES}

As características da CLAT na região da Indonésia caracterizam-se pela presença de uma CM diurna com altura próxima $0,3 \mathrm{~km}$ pela manhã e atingindo $3-5 \mathrm{~km}$ à tarde, observando-se um ciclo diurno de aquecimento e resfriamento, resultado semelhante encontrado por (Hashiguchi, et al. 1995b), exceto a forte influencia da circulação da brisa marítima no dia 12/10/1993. Conseguiu-se através de métodos estatísticos correlacionar os dados do BLR com os de radiossondagem na estação seca e chuvosa, onde na seca os coeficientes de regressão variaram entre 0,83 e 0,94 , tanto na direção como na intensidade, e na chuvosa variou entre 0,77 a 0,88 (intensidade) e no caso da direção da ordem de 0,3 .

Os resultados obtidos através destes dados mostraram que existem pronunciadas variações diurnas na CLA, em dias claros na região tropical, mas que estas apesar de usar o método dos perfis, semelhante as das latitudes médias (verão) encontradas na literatura, são bem mais profundas. Na estação chuvosa, a mistura atmosférica na $\mathrm{CM}$, não se desenvolveu, isso de se deve aos fracos fluxos de calor e cisalhamento do vento. Comprovou-se que as medidas de radar são equivalentes ao de radiossondagem, com o benefício de poder ter dados contínuos, provando que as observações, a partir da utilização do radar deve desempenhar um importante papel no estudo da baixa atmosfera tropical.

A existência da circulação de brisa marítima na região da Indonésia foi confirmada através do BLR. Com os dados de vento do BLR conseguiu-se representar a circulação da brisa marítima próximo à superfície que foi de $0,3-0,9 \mathrm{~km}$ e o fluxo de retorno de 1,5-2,0 km de altura, identificou-se que a circulação de brisa marítima tropical na estação seca tende a limitar a CM, durante o dia e modifica sensivelmente a estrutura da CLAT. No caso, do dia 12/10/93 notou-se que a circulação da brisa se desenvolveu às 1400 TL e a radiossondagem, mostrou que a profundidade total foi entre $1,5 \mathrm{e}$ $2 \mathrm{~km}$. De acordo, com os dados de superfície e de eco de radar conseguiu-se, realmente provar que o BLR pode observar a circulação da brisa marítima. Porém, a advecção horizontal e a estratificação modificada pela entrada da brisa afetaram os processos de transporte na CLAT, incluindo os fluxos turbulentos, aqui não exibidos.

Nota-se que a turbulência influenciou a intensidade do eco de radar, em função do gradiente de temperatura e umidade gerada pela atividade turbulenta através do cisalhamento mecânico. Os resultados obtidos neste trabalho têm implicações importantes para investigações futuras no estudo da baixa atmosfera em regiões tropicais, particularmente na questão que envolve a turbulência dentro da brisa marítima.

\section{AGRADECIMENTOS}

Os autores expressam os seus sinceros agradecimentos para aqueles que contribuíram para diagramação, sugestões e críticas a este trabalho, são eles: MSc. Marco Antônio Maringolo Lemes, Dr. Marco Antônio Lima Moura, Mariana Rocha de Camargo e MSc. Alessandro Sarmento Cavalcanti.

\section{REFERÊNCIAS BIBLIOGRÁFICAS}

ANGEVINE, W. M., et al. Boundary-layer depth and entrainment zone characterization with a boundary-layer profiler. Bound. Lay. Meteor., v. 68, n. 3, p. 375-385, 1994.

ARMIJO, L . A theory for the determination of wind and precipitation velocities with Doppler radars. J. Atmos. Sci., v. 26, n. 3, p. 570-573, 1969.

BOUSQUET, O.; CHONG M. A multiple-Doppler synthesis and continuity adjustment technique (MUSCAT) to recover wind components from Doppler radar measurements. J. Atmos. Ocean. Tech., v. 14, n. 2, p. 645-662, 1997.

BROWNING, K.; ATLAS, D. A. Velocity characteristics of some clear-air dot angels. J. Atmos. Sci., v. 23, n. 5, p. 592-604, 1966.

CHU, Y.H.; SU, C. L. Range resolution dependence of VHF radar returns from clear-air turbulence and precipitation. J. Atmos. Sol. Ter. Phys., v. 61, n. 4, p. 645-662, 1999.

DOVIAK, R. J.; CURRIER P. E., GREEN J. L. Field tests of a lower tropospheric wind profiler. Rad. Sci.,v. 25, n 6., p. 899-906, 1990.

DOVIAK, R. J.; ZRNIC, D.S. Doppler Radar and Weather Observations. San Diego: Academic Press. Inc., 1984. $453 \mathrm{p}$.

ECKLUND, W. L., et al. UHF wind profiler for the boundary layer: Brief description and initial results. J. Atmos. Ocean. Tech., v. 5, n. 3, p. 432-441, 1988.

GAGE, K. S.; BALSLEY, B. Doppler radar probing of the clear atmosphere. Bull. Am. Meteorol. Soc., v. 59, n. 9, p.1074-1094, 1992.

GAGE, K.S., et al. Use of Doppler radar for the measurement of atmospherics turbulence parameter from the intensity of clear-air echoes. Rad. Sci., v.15, n. 3, p.407 - 416. 1980. 
HASHIGUCHI, H., et al. Boundary Layer Radar Observations of the Passage of the Convection Center over Serpong, Indonesia $\left(6^{\circ} \mathrm{S}, 107^{\circ} \mathrm{E}\right)$ during the TOGA COARE Intensive Observations Period. J. Meteor. Soc. Japan, v. 73, n. 2B, p. 535 - 548, 1995(a).

HASHIGUCHI, H.; et al. Observations of the planetary boundary layer over equatorial Indonesia with and $\mathrm{L}$ band clear-air Doppler radar: Initial results. Rad. Sci.,v.30, n. 4, p. 1043-1054, 1995(b).

LHERMITTE, R. M. Probing air motion by Doppler analysis of radar clear air returns. J. Atmos. Sci., v. 23, n. 5, p. 575591, 1966.

MAY, P. T.; WILCZAK, J. M. Diurnal and seasonal variations of boundary layer structure observed with a radar wind profiler and RASS. Mon. Wea. Rev., v. 121, n. 3, p. 673682, 1993.

RIEHL, H. Meteorology Tropical. New York: McGraw-Hill Book Company, 1954. 392p.

ROGERS, R. R., et al. Research applications of a boundarylayer wind profiler. Bull. Am. Meteorol. Soc., v. 74, n. 4, p. 567-580, 1993.
SAUVAGEOT, H. Radar Meteorology. London: Antech House, 1992. 366 p.

SAUVAGEOT, H. Radarmétéorologie Télédétection Active de L'Atomsphère. Paris: Eyrolles, 1982. 296 p.

SORBJAN, Z. Structure of the Atmospheric Boundary Layer. New Jersey: Prentice-Hall, 1989. 317 p.

STULL, R. B. An Introduction to Boundary Layer Meteorology. Massachusetts: Kluwer Academic Norwell, 1988. $666 \mathrm{p}$.

TSUDA, T., et al. . A preliminary report on observations of equatorial atmosphere dynamics in Indonesia with radars and radiosondes. J. Meteor. Soc. Japan, v. 73, n. 2B, p. $393-406,1995$.

TSUDA, T., et al. Radiossonde observations of equatorial atmosphere dynamics over Indonesia, Part II: Characteristics of gravity waves. J. Geophys. Res., v. 99, n. 10, p. 10507 10516, 1994(b).

WYNGAARD, J.C; Le MONE, M. A. Behavior of the refractive index structure parameter in the entrainment convective boundary layer. J. Atmos. Sci., v. 37, n.7, p.1573-1585, 1980. 